\title{
Development and Deployment of a Precision Underwater Positioning System for In Situ Laser Raman Spectroscopy in the Deep Ocean
}

\author{
Sheri N. White ${ }^{1 *}$, William Kirkwood ${ }^{2}$, Alana Sherman ${ }^{2}$, Mark Brown ${ }^{2}$, \\ Richard Henthorn ${ }^{2}$, Karen Salamy ${ }^{2}$, Peter Walz ${ }^{2}$, Edward T. Peltzer ${ }^{2}$, and Peter G. Brewer ${ }^{2}$ \\ ${ }^{1}$ Dept. of Applied Ocean Physics \& Engineering, Woods Hole Oceanographic Institution \\ Woods Hole, MA 02543 \\ ${ }^{2}$ Research \& Development, Monterey Bay Aquarium Research Institute \\ 7700 Sandholdt Road, Moss Landing, CA 95039 \\ *Corresponding author \\ email: swhite@whoi.edu \\ phone: 508-289-3740 \\ fax: 508-457-2006
}




\title{
Development and Deployment of a Precision Underwater Positioning System for In Situ Laser Raman Spectroscopy in the Deep Ocean
}

\begin{abstract}
The field of ocean geochemistry has recently been expanded to include in situ laser Raman spectroscopic measurements in the deep ocean. While this technique has proved to be successful for transparent targets, such as fluids and gases, difficulty exists in using deep submergence vehicle manipulators to position and control the very small laser spot with respect to opaque samples of interest, such as many rocks, minerals, bacterial mats, and seafloor gas hydrates. We have developed, tested, and successfully deployed by remotely operated vehicle (ROV) a precision underwater positioner (PUP) which provides the stability and precision movement required to perform spectroscopic measurements using the Deep Ocean In Situ Spectrometer (DORISS) instrument on opaque targets in the deep ocean for geochemical research. The positioner is also adaptable to other sensors, such as electrodes, which require precise control and positioning on the seafloor. PUP is capable of translating the DORISS optical head with a precision of $0.1 \mathrm{~mm}$ in three dimensions over a range of at least $15 \mathrm{~cm}$, at depths up to $4000 \mathrm{~m}$, and under the normal range of oceanic conditions ( $T, P$, current velocity). The positioner is controlled, and spectra are obtained, in real time via Ethernet by scientists aboard the surface vessel. This capability has allowed us to acquire high quality Raman spectra of targets such as rocks, shells, and gas hydrates on the seafloor, including the ability to scan the laser spot across a rock surface in sub-millimeter increments to identify the constituent mineral grains. These developments have greatly enhanced the ability to obtain in situ Raman spectra on the seafloor from an enormous range of specimens.
\end{abstract}

Key Words: Optical Instruments, Underwater Vehicles, Oceanographic Equipment, Raman Spectroscopy, Motion Control 


\section{Introduction}

Early geochemical studies of the ocean floor relied upon dredges deployed from surface ships to pull up seafloor material for laboratory based analyses. As technology progressed, manned and unmanned submersibles have allowed scientists to actually view the ocean floor, to observe the changes from sedimented abyssal plains to rocky mid-ocean ridges (e.g., Ballard et al., 1975), and to visually select material for analysis. Today, imaging systems such as high definition video provide the most detailed images to date of the ocean floor with its enormous range of biological communities and geochemical sites, such as high-temperature hydrothermal vents and ice-like hydrate exposures.

Visual identification can provide only so much information. For example, a white solid object on the seafloor may be aragonite, calcite, barite, or anhydrite; and a hydrate exposure may have a wide range of chemical constituents, yet simply appear ice-like to the viewer. The ability to determine chemical structure, and to observe chemical processes in situ would be of great importance to users of deep submergence vehicles and platforms. Laser Raman spectroscopy is capable of performing these in situ measurements on solids, liquids and gases in the deep ocean (Brewer et al., 2004; Pasteris et al., 2004).

One challenge of deep-sea laser Raman spectroscopy is positioning the laser spot with the precision required to obtain spectra from opaque targets. To date, laser Raman spectroscopy has been limited to transparent objects because of the small focal depth (i.e., 0.15-3.0 $\mathrm{mm}$ ) sampling optics, and the difficulty of precise positioning of the focal spot by a deep submergence vehicle. ROV robotic arms are sometimes prone to jitter, and ocean forcing can cause vibrations of the ROV itself. These can result in the inability to properly position the laser spot, and the inability to maintain the position for the required data acquisition time. Solution of these problems would therefore greatly extend the generality of this technique, and its usefulness for ocean research. We have therefore developed a precision positioning system deployable by ROV for use with a deep-ocean laser Raman spectrometer. In this paper, we present the development of the Precision Underwater Positioner (PUP) for the acquisition of high quality Raman spectra of opaque targets on the seafloor. It should be noted that although PUP was designed for use with the DORISS instrument (Brewer et al., 2004), it is a stand-alone system that can be used with other sensors that have similar positioning requirements. 


\section{Background}

Laser Raman spectroscopy is a type of vibrational spectroscopy in which a monochromatic laser is used to excite a target and the inelastically backscattered light is measured (e.g., Nakamoto, 1997). The peaks observed in the Raman spectrum are due to the vibrational modes of the target molecule; thus information about both chemical composition and structure is obtained. Laser Raman spectroscopy is rapid, non-destructive, and can be performed in situ, making it a powerful tool for performing geochemical analyses in the ocean. In addition, it can be used to analyze solid, liquid or gaseous targets.

Brewer et al. (2004) developed and successfully deployed a sea-going laser Raman spectrometer (DORISS - Deep Ocean Raman In Situ Spectrometer). DORISS is based on a laboratory model Kaiser HoloSpec f/1.8i spectrometer (Owen et al., 1998) with a holographic transmissive grating and a $2048 \times 512$ CCD camera by Andor Technology. For deployment in the deep ocean (up to $4000 \mathrm{~m}$ depth) the components have been divided into three pressure housings. The housings containing the spectrometer, laser, and single-board computer are mounted in the ROV toolsled (Figure 1). The probe head is contained in a 35.5 $\mathrm{cm}$ long, $14 \mathrm{~cm}$ diameter titanium housing. It is connected to the laser and spectrometer via pressure-tolerant fiber optic cables. The probe head is carried on the front of the ROV and can be positioned at a target of interest with the ROV manipulator (Figure 2). DORISS has been deployed over a dozen times in Monterey Bay and the Gulf of California. It has been successfully used to perform gas dissolution experiments (White et al., in press), to analyze gas hydrates (Hester et al., in press), and to analyze natural gas venting from the seafloor (White et al., 2003).

\section{System Specification}

\subsection{Science Drivers}

The DORISS instrument has a very small focal volume - the laser spot size is on the order of tens of microns, and the depth of focus is as small as $\sim 0.15 \mathrm{~mm}$ in water (Figure 3). When analyzing transparent targets, the focal point is positioned inside the volume of the target. However, when analyzing an opaque target, the focal point must be positioned exactly at the surface of the material. This requires the ability to position the target with respect to the probe head with a precision of $\sim 0.1 \mathrm{~mm}$ in the direction normal to the surface. Using a 
larger depth-of-focus optic would ease the positioning requirements, but would decrease the power density, thus decreasing the Raman signal from the target.

The two approaches to precision positioning are: 1) present the target to a stationary probe head, or 2) present the probe head to the stationary target. The key advantage of DORISS over other techniques is the ability to nondestructively analyze a specimen in situ without any sample preparation or any sample alteration caused by sample collection, recovery, or storage. In order to maintain the experimental flexibility that DORISS provides, positioning the probe head is favored. During initial deployments of the DORISS instrument, the probe head was positioned with the ROV manipulator. This method was successful for analyzing transparent pools of liquid $\mathrm{CO}_{2}$ on the seafloor (Figure 2) and semitransparent samples of calcite. However, it was quite difficult to obtain spectra from opaque rock samples in this manner.

The Precision Underwater Positioner (PUP) was developed to provide the stability and precision positioning needed to collect quality Raman spectra of opaque targets on the seafloor (e.g., carbonates, hydrothermal minerals and bacterial mats). Ideally, the PUP would be generic enough to support the DORISS probe head in various configurations, and would be able to serve the needs of other types of instrumentation that may require precision positioning (e.g., deep sea microscopy).

\subsection{Design Concept}

Several concepts were considered to meet the functional requirements (listed in the Appendix) including a 3 degree of freedom (DOF) Cartesian system (i.e., $\mathrm{X}-\mathrm{Y}-\mathrm{Z}$ ) and a 6 DOF Stewart platform (i.e., hexapod). The X-Y-Z and hexapod platforms did not provide adequate flexibility for DORISS operations, and could not easily meet the size and weight requirements. The concept selected was a 5 DOF system (Figure 4A). The axes of motion are $\mathrm{Z}$ (up-and-down), R (in-andout), and theta (rotation about the $Z$ axis). A pan \& tilt device at the sensor head provides the remaining 2 degrees of freedom. A tripod platform is used for stability with adjustable legs to accommodate various seafloor topologies. By off-loading PUP onto the seafloor, it is decoupled from any ROV motion. A small web camera, light, and lasers are mounted on the sensor head to aid in positioning. The two lasers are positioned to cross at the focal point of the DORISS laser beam. The camera allows the user to observe the locations of the 
DORISS laser and the positioning lasers on the target. The laser spots move closer to one another as the DORISS focal spot approaches the surface of the target.

Because of time and resource limitations, the phase I prototype consists of 3 $\operatorname{DOF}(Z, R$, and theta), with rigid legs, and a camera, light and lasers (Figure 4B). Additional axes and features will be added as time and resources permit.

\section{System Build}

A system block diagram for the DORISS/PUP system is shown in Figure 5 . PUP consists of actuators, a camera, light, lasers, and electronics (e.g., servos, motion controllers, Ethernet hub and video server) in a single off-loadable unit. As noted above, the DORISS electronics and spectrometer housing are mounted in the ROV toolsled. An additional housing, the vehicle interface can (VIC), is also mounted in the toolsled and provides a single power and communications interface to the ROV for both DORISS and PUP. Note that DORISS and PUP can each be used individually on the ROV without the VIC housing. The ROV provides power (ROV Tiburon: 240 VDC; ROV Ventana: 110 VAC) and communications via the Ethernet protocol. The system is controlled by the ROV pilots and scientists in a control room aboard the support ship.

\subsection{Mechanical}

The mechanical components can be broken down into thee categories: the actuators and ways, the frame, and the electronics housing. Other than the frame weldment and the DORISS probe head mount, most of the PUP mechanical components were purchased as commercially-off-the-shelf (COTS) technology.

The electric linear actuators used on PUP were purchased from Exlar Corporation, a manufacturer of oil-cooled, high precision linear actuators. These oil-filled actuators were easily adaptable for high-pressure deep-sea applications. A closed-loop pressure compensation design provides approximately 6 to 10 psi of pressure over ambient, insuring that no seawater will migrate into the system. A custom manifold was designed and manufactured at MBARI that integrated the three standard connector openings from the manufacturer. The manifold allowed for a single connector, thereby reducing the overall cost for underwater connectors, increasing the reliability by 
limiting the number of wet connections, and minimizing the number of cables between the various moving stages of PUP.

Because of the cantilever loading of the actuator by the sensor head, structural ways (pathways) are required to provide stability and stiffness. Two sets of guide ways were constructed: the common trapezoidal cross section (dovetail) found in precision tooling applications; and a U-shaped cross-section design (Figure 6A) which allows for lightening holes and the use of more plastic for stabilizing portions of the design. The sliding rail components for both sets were constructed in stainless steel and the stationary guides were constructed from Delrin ${ }^{\mathrm{TM}}$. After initial testing and some modifications from the initial design, the U-shaped ways were selected for the final design based on the stiffness to weight ratio. Each linear axis has a matched set of opposing ways to support the cantilevered system weight while delivering the low stiction (static friction) performance required for smooth operation over fine-scale command inputs. The rotational axis uses the same modified Exlar linear actuator to drive the motion of a rotational bearing (Figure 6B). The free flooded bearing design is a modification to the traditional angular contact bearing. Single angular contact bearings are capable of continuous thrust in one direction only. This design uses two integrally opposed angular contact bearings to allow for both moment and thrust loading in either direction. The use of Bellville washers in the bearing assembly provides an adjustable pre-load on the bearing set. The bearing material is Titanium $6 \mathrm{AL} 4 \mathrm{~V}$. This material choice provides very good corrosion resistance combined with light weight and superior strength.

The supporting framework of PUP is a weldment constructed of 6061 aluminum heat treated to the T6 condition. The frame is lightweight while also providing the strength for positioning stability during operations. Three rigid legs are bolted on at mounting points on the corners of the frame. These legs can be replaced with adjustable legs on the next generation PUP. Different feet designs can also be used depending on the seafloor terrain. For example, flat plates were used for deployments on soft sediment to prevent subsidence. A polypropylene bridle fixed at the three corners of the frame serve as a lifting harness (Figure 7).

A Benthos glass sphere, commonly used for deep-sea applications, was selected for the pressure housing (Figure 8). The glass sphere was chosen primarily for cost and weight. The glass sphere is mounted in the frame with a 
standard Benthos polyethylene hardhat which provides an easy means for attachment while also giving the sphere protection from impact.

The total weight of the PUP system is $106 \mathrm{~kg}$. in air (39 kg. in water). When used with DORISS, the probe head is mounted on PUP adding an additional 12 $\mathrm{kg}$. in air (6 kg. in water). Lead weights were added to the rear leg such that PUP would hang trim from the lifting harness (the glass sphere does not sufficiently counterbalance the extended probe head).

\subsection{Electrical}

All the electronics needed to power and control PUP's motors, lasers, camera, and light are housed in a glass sphere (Figure 8). Each actuator requires a stand-alone motion controller (DMC-2183, Galil Motion Control, Inc.) and digital servo drive (DR100RE30A40NDC, Advanced Motion Controls). The actuators are equipped with a resolver, which was chosen over other position sensors because it was easy to integrate into the oil-filled environment. Consequently, the digital servo drives were selected primarily because they feature resolver-based commutation; they also provide an emulated encoder output. These encoder signals provide feedback for the motion controller's position servo loop. The actuators also are equipped with two Hall effect sensors that are triggered as the shaft passes through the home position and the forward limit. The motion controller monitors the status of these limit switches. During early sea trials these limit switches experienced false triggering, which would result in the motion controller locking the motor. It was determined that noise of the $24 \mathrm{~V}$ power lines to the switches was causing the false triggering. This was remedied by placing tantalum capacitors across the power lines.

In addition to motor drive electronics, the PUP sphere houses electronics for peripheral devices mounted on the probe head including: an underwater camera (DeepSea Power and Light, Multi Seacam 2050), a pair of $635 \mathrm{~nm}$ crossing lasers (C-Map Systems Inc, SLD10), and a custom LED light. The video signal from the underwater camera is fed into a video server (AXIS 2400, Axis Communications). The video server and the motion controller are both TCP/IP compatible, so all communications to the PUP system are through the Ethernet protocol. Two relay boards are used to switch the power provided to the camera, lasers, and lights. Since both the lights and the lasers would affect the Raman spectra during collection, it is necessary for the user to be able to turn 
these components off during spectral acquisition. Additionally, the sphere houses two sensor boards (900-45T, Applied Geomechanics Inc.) which measure pressure, water, humidity, temperature, and tilt. The signals from these sensors feed into an analog I/O board (DB-20840, Galil Motion Control, Inc.) attached to the motion controller. The values of these sensors are displayed on a GUI so the user can monitor environmental conditions. The tilt meter reading provides valuable information when working on uneven areas of the seafloor or on soft sediment.

PUP is connected to the ROV by a single cable which provides power and communications. MBARI's two ROVs have different power availability: ROV Ventana provides $120 \mathrm{VAC}$, and ROV Tiburon provides $240 \mathrm{VDC}$. Most of the power needs were satisfied by off the shelf power supplies which were compatible with both the AC and DC inputs. A commercial 12 VDC supply provides power to an Ethernet switch, and the relay boards. A 24 VDC supply provides power to the motion controller, video server, and Hall effect switches. A custom power supply, which accepts either 120 VAC or 240 VDC as input, was built to provide power to the motor drivers.

\subsection{Software}

In an effort to accelerate development and improve quality, the project team re-used the Cline et al. (2001) software design and code framework from the Environmental Sample Processor (ESP) which has similar precision motion control requirements. The object-oriented framework software was developed and implemented in C++, using Microsoft's Visual Studio. Reusing the code from ESP allowed the PUP team to focus immediately on the particular motion control requirements of the PUP, saving significant development hours. Moreover, the Cline et al. (2001) framework code had been tested and in use for a number of years, proving to be a capable and reliable foundation upon which to build the PUP software.

The framework includes a number of core object classes intended to work within a variety of motion control applications. The 3 axes of the PUP are represented with 3 Axis objects, each containing a Motor object. The main application dialog takes the actions from the user and translates them into the appropriate calls to member functions of the Axis and Motor objects. Adding axes to the system simply requires adding Axis/Motor object pairs to the 
application and useful controls to the PUP dialog along with the translation code.

The Axis and Motor classes are designed to work with a generic controller system, using generalized controller function commands. Housed within the glass sphere, the Galil Motion Control unit handles all the low-level motor control logic. Galil provides software and a simple API and command language to move the motor in the desired direction and linear distance. The application developer integrated the specific Galil controller into the framework by deriving a new class from the generic controller class, overriding the generalized member functions, and providing a translation for the linear distance to motor controller units.

The PUP graphical user interface (GUI) was designed to offer a simple control interface to accommodate deployments with users unfamiliar with the system design and development. As a result, the interface is straightforward, intuitive, and easy to use (Figure 9). Top left section of the GUI shows the environmental conditions inside the sphere, tilt angles, and motor error states. The middle left section is devoted to motion control. Arrow buttons are used for incremental movement of the Theta, $R$, and $Z$ axes with current position displayed above them. Below the increment arrows are controls that allow the user to change the incremental movement distance and the absolute motor speed. Direct positioning controls allow the user to enter the $Z, R$, and Theta axis positions and command PUP to move the actuators directly to that position. The bottom left section of the GUI contains buttons for turning devices on the PUP on and off: a pair of crossing lasers, the camera, an LED light, and DORISS. The middle portion of the dialog is used for storing and recalling positions of interest that the user may want to revisit or document. The right side of the dialog are controls for commanding the Galil controller directly using the Galil command language. The user types commands in the upper edit box while the response from the controller is written to the lower edit box. This feature is useful for troubleshooting and experimenting with unusual movements.

\section{Testing}

\subsection{Sub-system testing}

The actuators were tested to verify that PUP could provide the precision movement stipulated in the functional requirements $(0.1 \mathrm{~mm}$ increments $)$. The 
actuators were found to be capable of motion in increments smaller than 0.05 $\mathrm{mm}$. A small amount of backlash $(+/-0.0127 \mathrm{~mm})$ was measured when the direction of travel was changed (Figure 10).

A key concern during the development of the PUP was the rigidity of the actuators. The linear actuators were modified from the "as-built" mechanisms received from the vendor to provide a stiff assembly capable of carrying the weight of the probe head. Early prototype testing of the slide sub-assembly under various load conditions was performed to verify that the system could meet the load requirements and to characterize the flexure in the system. The load testing was conducted for $1 \mathrm{~cm}$ incremental extensions of the slide mechanism up to $15 \mathrm{~cm}$. Loads were increased in $20 \mathrm{lb}(9.1 \mathrm{~kg})$ increments from 25 to $85 \mathrm{lbs}(11.3 \mathrm{~kg}$ and $38.5 \mathrm{~kg})$. The data revealed that the system behaves repeatably and can be characterized mathematically (Figure 11). For a $25 \mathrm{lb}(11.3 \mathrm{~kg})$ load, the deflection is just within our precision requirement of $0.10 \mathrm{~mm}$. The DORISS probe head is $13 \mathrm{lbs}(5.9 \mathrm{~kg})$ in water.

\section{2. $\quad$ System testing}

Once PUP was fully assembled, tests were performed with the DORISS instrument to verify PUP's ability to precisely position the DORISS probe head. This testing was performed with the DORISS immersion optic, which has a focal depth of $\sim 0.15 \mathrm{~mm}$ in water (Figure 3 ) and $\sim 0.2 \mathrm{~mm}$ in air. The DORISS probe head was mounted on PUP in a downward-looking orientation (i.e., the $\mathrm{Z}$ axis was used for focusing). The test target was a polished silicon wafer which is a strong Raman scatterer with stringent positioning requirements. The focus mode in HoloGRAMS continuously acquires spectra at a user-defined exposure time and rapidly displays the spectra on the computer screen. The user focuses DORISS by moving the probe head in small increments until the Raman band of interest (in this case the $520 \Delta \mathrm{cm}^{-1}$ silicon band) is maximized. The PUP and DORISS software systems are not integrated so there is currently no automated focusing. We were able to successfully obtain spectra of the silicon wafer and other mineral targets using PUP to focus the DORISS probe head.

In order to determine the repeatability of the system, we used a polished silicon wafer that was masked by a thin aluminum plate with a $1 \mathrm{~mm}$ diameter hole. Repeatability allows one to return to a point of interest on a heterogeneous sample. A system with good repeatability can also be used to 
determine distances between locations, or movement of the target or PUP (e.g., sinking into soft sediment). The DORISS optic was focused onto the silicon wafer in air through the $1 \mathrm{~mm}$ hole. The initial position of the actuators was $\mathrm{Z}$ $=100 \mathrm{~mm}, \mathrm{R}=100 \mathrm{~mm}$, and Theta $=30$ degrees. After a spectrum was obtained, each actuator was moved to the home position and commanded back to the position at which the first spectrum was taken. The spectra acquired after the $\mathrm{Z}$ and $\mathrm{R}$ axes were moved matched the initial spectrum very well, thus verifying the ability to return to a previous position with a high degree of accuracy. After the Theta axis was moved, the spectrum was slightly weaker $(\sim 5 \%)$ than the initial spectrum (Figure 12A). Next, all three axes were moved throughout their ranges of motion repeatedly, then returned to the initial location. This time the silicon wafer could not be detected. After jogging the actuators slightly, the silicon spectrum was reacquired and maximized. The spectrum acquired at this location matched the initial spectrum very well (Figure 12B). The new position was $\mathrm{Z}=99.9 \mathrm{~mm}, \mathrm{R}=100.0$, theta $=29.8$ degrees. Based on this experiment, the repeatability of the actuators was measured to be approximately $+/-0.1 \mathrm{~mm}$ for the $\mathrm{Z}$ axis. Since a $1.0 \mathrm{x} 1.0 \mathrm{~mm}$ mask was used in the horizontal plane, we can only state that the $\mathrm{R}$ and theta axes are repeatable to within $\sim 1.0 \mathrm{~mm}$.

\section{Field Results}

PUP and DORISS have been deployed a number of times in the deep ocean for testing, and exploratory measurements. Field deployments in Monterey Bay to depths as great as $1022 \mathrm{~m}$ provided the opportunity to test all of the components of the PUP system, and to solve minor problems related to the effects of the cold, high-pressure deep-sea environment. Additionally, Raman spectra were acquired with the DORISS instrument which proved the necessity and effectiveness of PUP.

Known samples of marble, granite and other rocks were carried to the seafloor for Raman analysis. With PUP, we were able to successfully collect spectra from these solid, opaque targets, and we collected spectra along profiles and grid patterns in increments as fine as $0.1 \mathrm{~mm}$. Figure 13 compares spectra from a slab of marble obtained on the seafloor and in the lab using PUP to position the DORISS probe head. The seafloor spectrum is slightly noisier than the lab spectrum, but compares quite favorably. The O-H stretching bands of 
water present in the seafloor spectrum are due to the seawater in the optical path.

A slab of granite was analyzed on the seafloor to test the ability of DORISS/PUP to scan over a heterogeneous sample and to obtain information about the bulk composition (Figure 14). This type of point-counting technique is described by Haskins et al. (1997). We conducted two grid scans over the granite sample. The first consisted of 20 points in a 5 x 4 grid of $0.1 \mathrm{~mm}$ increments. This grid mapped out a grain of the mineral albite bounded on one side by microcline, and on one corner by quartz (Figure 15). Most of the spectra indicated a single mineral at each point. One point on the albite-quartz boundary contained peaks from both minerals. A second grid of $5 \mathrm{~mm}$ increments was used to collect data to determine information about the bulk composition of the rock. Because of time limitations, spectra were collected from only a 3 x 3 grid (with points numbered 1-9). While the number of data points is too low for a statistically significant analysis, the data do show the expected trends. The minerals identified are listed in Table 1, and a few representative spectra are shown in Figure 16. In most cases, the spectra at each point indicated a single mineral. For cases in which two minerals were detected, they were each assigned half an occurrence, regardless of their relative peak intensities, for the calculation of abundance, as done by Haskins et al. (1997). The chemical composition determined by the Raman point-counting analysis is similar to the average granite composition (Table 2). While granite is not expected to be a target for deep-sea Raman work, this test case provides an example of how DORISS, with the positioning capabilities provided by PUP, can be used to determine bulk rock compositions.

We also attempted to collect spectra from natural targets in the deep ocean. Using PUP we were able to collect a Raman spectrum from a piece of shell (Figure 17) located at the base of Invert Cliff in Monterey Bay (1024 m depth). In the spectrum we observe the $1086 \Delta \mathrm{cm}^{-1}$ peak of calcium carbonate. By looking at the weaker bands present in the lower wavenumber region we were able to determine that calcite and aragonite (polymorphs of $\mathrm{CaCO}_{3}$ ) are both present. Although these two minerals have the same chemical composition, their structure is slightly different which results in distinct Raman peaks. Calcite exhibits minor peaks at $\sim 281$ and $\sim 711 \Delta \mathrm{cm}^{-1}$, while the aragonite minor peaks are located at $\sim 206$ and $\sim 705 \Delta \mathrm{cm}^{-1}$ (Urmos et al., 1991). 
Some spectra of natural targets were obtained serendipitously. While acquiring spectra from the granite sample on the seafloor, a marine snail climbed onto the sample and approached the laser beam. Because the immersion optic was $\sim 1 \mathrm{~mm}$ from the granite sample, the snail could not move fully into the laser path. However in those spectra we were able to detect carotenoids, which we believe come from the snail shell (Figure 18). Carotenoids produce strong resonance Raman bands that have been previously observed in Raman spectra of snail shells and corals (e.g., Urmos et al., 1991; Withnall et al., $2003)$.

Operations were also carried out in Monterey Bay to test the ability of DORISS/PUP to collect in situ Raman spectra of gas hydrates in preparation for an expedition to Hydrate Ridge, Oregon. Synthetic hydrates were created in a sample cell from a methane-ethane gas mixture at a depth of $1022 \mathrm{~m}$. In this case, the DORISS probe head was mounted horizontally such that the theta axis was used for focusing. PUP was successfully able to focus the laser spot onto the hydrate such that quality Raman data could be obtained (Hester et al., in press).

\section{Conclusions}

Laser Raman spectroscopy is a valuable geochemical tool for performing in situ analyses of a variety of targets in the deep ocean. The DORISS instrument has already been shown to be effective in analyzing transparent and semitransparent targets. The Precision Underwater Positioner (PUP) greatly enhances the DORISS instrument by allowing it to obtain in situ Raman spectra of opaque targets as well. PUP provides the ability to move in sub-millimeter increments and to scan over the surface of a target in order to perform analyses on the scale of mineral grains. This capability is unique and will lead to new analyses that will further our understanding of various environments in the deep ocean such as natural gas vents, hydrothermal venting sites, geologic formations, hydrate studies, and microbial communities. While PUP was developed for the DORISS instrument, it is capable of being used for any deep ocean sensor with similar positioning requirements. 


\section{Acknowledgements}

We thank the officers and crews of the R/V Point Lobos and R/V Western Flyer, and the ROV teams of Ventana and Tiburon, for their skill and support at sea; collaborator John Freeman of Washington University, St. Louis; Jill Pasteris of Washington University, St. Louis for use of the granite sample; the technical support of John Ferreira, Jim Scholfield, Randy Pricket, Duane Thompson, Tom Marion, and Jose Rosal; and the comments of the editor and three anonymous reviewers. Funding was provided by a grant to MBARI from the David and Lucile Packard Foundation. 


\section{Appendix}

\section{Functional Requirements}

Functional requirements were developed to specify the features needed in a precision underwater positioner. These include general requirements on how the system will be used and specific performance requirements (Table 3). The performance requirements were based on the operational needs of the DORISS system (i.e., motion and stability requirements) and the operations and limitations of MBARI's two remotely operated vehicles - ROV Tiburon and ROV Ventana (i.e., physical size, electrical, and environmental requirements).

\section{GENERAL REQUIREMENTS}

1. Shall be capable of operating in stand-alone mode (in air or water) for in-lab use and testing

2. Shall be deployed on the seafloor by an ROV

2.1. Shall be powered by the ROV

2.2. Shall accommodate the DORISS stand-off distance of $5 \mathrm{~m}$

3. Shall maintain stability over full range of motion

3.1. Shall accommodate uneven ocean floor (e.g. slopes up to 30 degrees)

3.2. Shall accommodate a variety of seafloor surfaces (e.g., rocks, sediment, mud)

4. Shall accommodate a sensor head in either the horizontal or vertical orientation

4.1. May be capable of changing orientation during deployment

5. Shall be capable of positioning the laser beam normal to some optimal plane associated with the target

6. Shall have one external camera mounted to the sensor mount for positioning

6.1. Shall have external lighting

6.2. Shall have two crossing lasers for positioning reference to assist the pilots in placing the positioner in the appropriate location

7. Shall be controlled by a shipboard scientist

7.1. Shall have user interface software capable of control and display

7.2. Shall have position feedback

7.3. Shall have dual speed positioning

8. May accommodate other (non-DORISS) sensors 


\section{References}

Ballard, R., Bryan, W. B., Heirtzler, J. R., Keller, G., Moore, J. G., and van Andel, T. H., 1975, Manned submersible observation in the FAMOUS area: Mid-Atlantic Ridge: Science, v. 190, no. 4210, p. 103-108.

Brewer, P. G., Malby, G. E., Pasteris, J. D., White, S. N., Peltzer, E. T., Wopenka, B., Freeman, J., and Brown, M. O., 2004, Development of a laser Raman spectrometer for deep-ocean science: Deep-Sea Res. I, v. 51, p. DOI:10.1016/j.dsr.2003.11.005.

Clark, S. P., 1966, Composition of rocks, in Clark, S. P., ed., Handbook of Physical Constants: New York, The Geological Society of America, p. 15 .

Cline, D., O'Reilly, T. C., Meese, T., Roman, B., and Edgington, D. R., 2001, The Environmental Sample Processor (ESP) software design: Software for detection and quantification of microorganisms, in IEEE/MTS Oceans 2001, Honolulu, HI, p. 287-294.

Haskin, L. A., Wang, A., Rockow, K. M., Jolliff, B. L., Korotev, R. L., and Viskupic, K. M., 1997, Raman spectroscopy for mineral identification and quantification for in situ planetary surface analysis: A point count method: J. Geophys. Res., v. 102, no. E8, p. 19,293-19,306.

Hester, K. C., White, S. N., Peltzer, E. T., Brewer, P. G., and Sloan, E. D., in press, Raman spectroscopic measurements of in situ ocean clathrate hydrates: Mar. Chem.

Nakamoto, K., 1997, Infrared and Raman Spectra of Inorganic and Coordination Compounds: Part A: New York, NY, John Wiley \& Sons, Inc., 387 p.

Owen, H., Battery, D. E., Pelletier, M. J., and Slater, J., 1998, New spectroscopic instrument based on volume holographic optical elements: Proc. SPIE, v. 2406, p. 260-267.

Pasteris, J. D., Wopenka, B., Freeman, J. J., Brewer, P. G., White, S. N., Peltzer, E. T., and Malby, G. E., 2004, Raman spectroscopy in the deep ocean: successes and challenges: Appl. Spec., v. 58, no. 7, p. 195A-208A.

Urmos, J., Sharma, S. K., and Mackenzie, F. T., 1991, Characterization of some biogenic carbonates with Raman spectroscopy: American Mineralogist, v. 76, p. 641-646.

White, S. N., Brewer, P. G., and Peltzer, E. T., in press, Determination of gas bubble fractionation rates in the deep ocean by laser Raman spectroscopy: Mar. Chem.

White, S. N., Brewer, P. G., Peltzer, E. T., Kirkwood, W. J., Pasteris, J. D., and Nakayama, N., 2003, First expeditionary deployments of the Deep Ocean Raman In Situ Spectrometer: Eos Trans. AGU, v. 84, no. 46, p. Fall Meet. Supp1., Abstract OS32A-0235.

Withnall, R., Chowdhry, B. Z., Silver, J., Edwards, H. G. M., and de Olivera, L. F. C., 2003, Raman spectra of carotenoids in natural products: Spectrochim. Acta A, v. 59, p. 2207-2212. 


\section{Figure Captions}

Figure 1. DORISS and PUP being deployed on the ROV Ventana. The DORISS electronics and spectrometer housings are mounted in a drawer in the back of the ROV toolsled. The DORISS probe head and the PUP are carried on the front porch and secured by the ROV manipulator.

Figure 2. The DORISS probe head is positioned over a pool of liquid on the seafloor (3607 $\mathrm{m}$ depth) by the ROV manipulator. The fiber optic cables connecting the probe head to the DORISS electronics and spectrometer housings can be seen on the left.

Figure 3. The depth of focus of the immersion optic is determined by collecting spectra from a polished silicon wafer. As the optic is moved in $0.1 \mathrm{~mm}$ increments, the intensity of the characteristic $520 \Delta \mathrm{cm}^{-1}$ peak of silic on is measured. The full width at half maximum (FWHM) is the depth of focus ( $\sim 0.15 \mathrm{~mm}$ for this optic).

Figure 4. (A) The design concept for the precision underwater positioner (PUP) calls for a tripod platform with 5 degrees of motion: Z (up-and-down), R (in-and-out), Theta (rotation about the Z-axis), and pan and tilt at the probe head (alpha and beta in the figure). Two lasers and a camera are shown mounted to the sensor head to aid in positioning. (B) The prototype design consists of 3 degrees of motion all driven by linear actuators, rigid legs, a camera, and lasers.

Figure 5. Block diagram of the DORISS (gray boxes) and PUP (white boxes) system. DORISS consists of three housings: the electronics and spectrometer housings are mounted in the toolsled, and the probe head housing is mounted on the PUP. PUP consists of electronics housed in a glass sphere which control the actuators, camera and lasers. PUP and DORISS are connected to the ROV through a vehicle interface can (VIC). The ROV provides communications via the Ethernet protocol and power.

Figure 6. (A) The PUP actuators were purchased from Exlar and modified. Ways were mounted directly to the actuator housing to add rigidity. A custom manifold was designed to integrate the three standard connector openings to a single connection. (B) The rotation axis is a stainless steel bearing driving by a linear actuator. The actuators are oil-filled and a closed-loop compensator provides 6-10 psi of pressure over ambient.

Figure 7. PUP sitting on the seafloor at $1022 \mathrm{~m}$ depth in Monterey Bay. The rope bridle is used for lifting PUP with the ROV manipulator. The R axis is fully extended, and the $\mathrm{Z}$ and Theta axes are fully retracted in this picture. The diffuse green laser spot from the DORISS probe head can be seen on the sediment.

Figure 8. The PUP electronics are housed in a Benthos glass sphere. The electrical components include a power supply, motion controllers, servo amplifiers, a video server and an Ethernet hub. Six penetrations provide connection to the three actuators, the camera, the lights and lasers (single connector), and the ROV for power and communications. 
Figure 9. The PUP GUI allows the shipboard scientist to monitor conditions inside the electronics sphere, control PUP's motion, and control power to the lights, camera, lasers, and DORISS (left side). Position locations can be stored and recalled (center panel). The right side allows the user to input commands directly to the motor controllers.

Figure 10. The PUP actuators are capable of moving in increments smaller than $0.05 \mathrm{~mm}$. The actuators move in the precise increments commanded by the user. However, when the direction is changed, the system exhibits a small amount of backlash $(+/-0.0127 \mathrm{~mm})$.

Figure 11. The actuator sub-assembly was tested under various load conditions to determine deflection. At full extension $(15 \mathrm{~cm}$ ) the deflection is $\sim 0.1$ for a $11.3 \mathrm{~kg}$ (25 lbs) load to $\sim 0.25$ $\mathrm{mm}$ for a $20.4 \mathrm{~kg}$ (45 lb.) load. The DORISS probe head is $13 \mathrm{lbs}(5.9 \mathrm{~kg})$ in water.

Figure 12. Raman spectra of a polished silicon wafer obtained using DORISS and PUP. The red line is the initial spectrum collected at position $Z=100.0 \mathrm{~mm}, \mathrm{R}=100.0 \mathrm{~mm}$, Theta $=30.0 \mathrm{deg}$. In plot $A$, the blue dashed-dotted line was collected after the $Z$ axis was retracted then returned to the same position. The green dashed line was collected after both the $\mathrm{Z}$ and $\mathrm{R}$ axes were retracted then returned to the same position. The purple line was collected after all three axes $(Z$, $\mathrm{R}$, and Theta) were retracted then returned to the same position. In plot $\mathrm{B}$, the blue line was collected after all three axes had been moved back and forth throughout their full ranges of motion. The position during the collection of this spectrum was $(Z=99.9 \mathrm{~mm}, \mathrm{R}=100.0 \mathrm{~mm}$, Theta $=29.8 \mathrm{deg})$.

Figure 13. Spectrum of marble sample (A) on the seafloor at $1022 \mathrm{~m}$ depth and (B) in the lab using PUP to position the focal spot. The immersion optic with a focal depth of $0.15 \mathrm{~mm}$ in water was used on the DORISS probe head. Marble is characterized by peaks at $\sim 302,725$, 1098 , and $1441 \Delta \mathrm{cm}^{-1}$. The $\sim 1332 \Delta \mathrm{cm}^{-1}$ band is from a diamond plate in the probe head to provide a calibration reference. The water stretching bands can be seen at longer wavenumbers in the seafloor data. The peaks on the right of the spectrum are due to impurities in the sapphire pressure window of the immersion optic.

Figure 14. A slab of Rapakivi granite (from J. Pasteris, Washington University) carried to the seafloor for DORISS/PUP testing.

Figure 15. A $5 \times 4$ grid in $0.1 \mathrm{~mm}$ increments of the granite slab. The location of the data points is shown in the figure on the left. The mineral at each point is shown in the figure on the right. Mineral identification was performed solely by Raman spectroscopy. The minerals identified were quartz (Qtz), albite (Alb) and Microcline (Mic).

Figure 16. Spectra of the granite sample on the seafloor at $1022 \mathrm{~m}$ depth using PUP to position the DORISS focal spot. These spectra were collected in a grid pattern with $5 \mathrm{~mm}$ spacing. The primary mineral components can be seen to be quartz and feldspar: albite (plagioclase feldspar) and microcline (potassium feldspar). The peaks at $1332 \Delta \mathrm{cm}^{-1}$ are from the diamond calibration reference. The dashed lines indicate the primary albite bands $\sim 290,479$, and $507 \Delta \mathrm{cm}^{-1}$. 
Figure 17. Spectrum of a shell fragment found on the seafloor at $1022 \mathrm{~m}$ depth. The DORISS probe head was positioned using PUP. From the Raman spectrum one can observe that calcite and aragonite (polymorphs of $\mathrm{CaCO}_{3}$ ) are both present.

Figure 18. Spectra from a $0.1 \mathrm{~mm}$ profile of granite. All of the spectra are of the mineral albite (plagioclase feldspar). The bottom three spectra show peaks at $\sim 1159$ and $1524 \Delta \mathrm{cm}^{-1}$ (dashed lines) which are indicative of the carotenoid beta-carotene. The carotenoid appears to come from the shell of a snail that came close to the beam during our acquisitions.

\section{Tables}

Table 1. Point-counting data from a granite sample $(3 \times 3,5 \mathrm{~mm}$ increment grid $)$

\begin{tabular}{lccccc}
\hline \multicolumn{1}{c}{ Mineral } & \% of Grid & Single & Mixed & \multicolumn{2}{c}{ Point Number } \\
\cline { 5 - 6 } & & $(\mathbf{N})$ & $(\mathbf{N})$ & Single & Mixed \\
\hline Quartz $\left(\mathrm{SiO}_{2}\right)$ & $39 \%$ & 2 & 3 & 2,5 & $1,7,9$ \\
Albite $\left(\mathrm{NaAlSi}_{3} \mathrm{O}_{8}\right)$ & $28 \%$ & 2 & 1 & 4,6 & 1 \\
Microcline $\left(\mathrm{KAlSi}_{3} \mathrm{O}_{8}\right)$ & $28 \%$ & 2 & 1 & 3,8 & 9 \\
\hline
\end{tabular}

Table 2. Major chemical components of granite

\begin{tabular}{lcc}
\hline Oxide & $\begin{array}{c}\text { From Raman data } \\
\text { of granite sample } \\
\text { Weight } \%\end{array}$ & $\begin{array}{c}\text { Average granite } \\
\text { composition* } \\
\text { Weight } \%\end{array}$ \\
\hline $\mathrm{SiO}_{2}$ & 63.6 & 70.18 \\
$\mathrm{Al}_{2} \mathrm{O}_{3}$ & 9.0 & 14.47 \\
$\mathrm{~K}_{2} \mathrm{O}$ & 4.5 & 4.11 \\
$\mathrm{Na}_{2} \mathrm{O}$ & 4.5 & 3.48 \\
\hline
\end{tabular}

* From (Clark, 1966) 
Table 3. Performance Requirements

\begin{tabular}{ll}
\hline Requirements & Specified Value \\
\hline Motion requirements (for each dimension) & \\
Minimum position travel of the beam spot & $15 \mathrm{~cm}$ \\
Maximum travel increment of the beam spot & $0.1 \mathrm{~mm}$ \\
Maximum time to travel full range & 1 minute \\
Relative accuracy & $1 \mathrm{~mm}$ \\
Pan and tilt range (horizontal or vertical orientation) & $+/-45$ degrees \\
Physical size requirements & \\
Maximum sensor weight (in air) & $30 \mathrm{~kg}$ \\
Maximum sensor size allowed on mounting surface & $60 \mathrm{x} 20 \mathrm{x} 20 \mathrm{~cm}$ \\
Maximum weight of complete system (in air) & $100 \mathrm{~kg}$ \\
Maximum stowed size (W x H x D) & $122 \mathrm{~cm} \mathrm{x} 61 \mathrm{~cm} \times 61 \mathrm{~cm}$ \\
Electrical requirements & \\
Input Power & $240 \mathrm{VDC}$ or $110 \mathrm{VAC}$ \\
Environmental requirements & \\
Operating depth limit & $4000 \mathrm{~m}$ \\
Operating temperature (ambient) & $0-50 \mathrm{degrees} \mathrm{C}$ \\
Operating current (water velocity) & $0-5 \mathrm{knots}$ \\
\hline
\end{tabular}


Figure 1

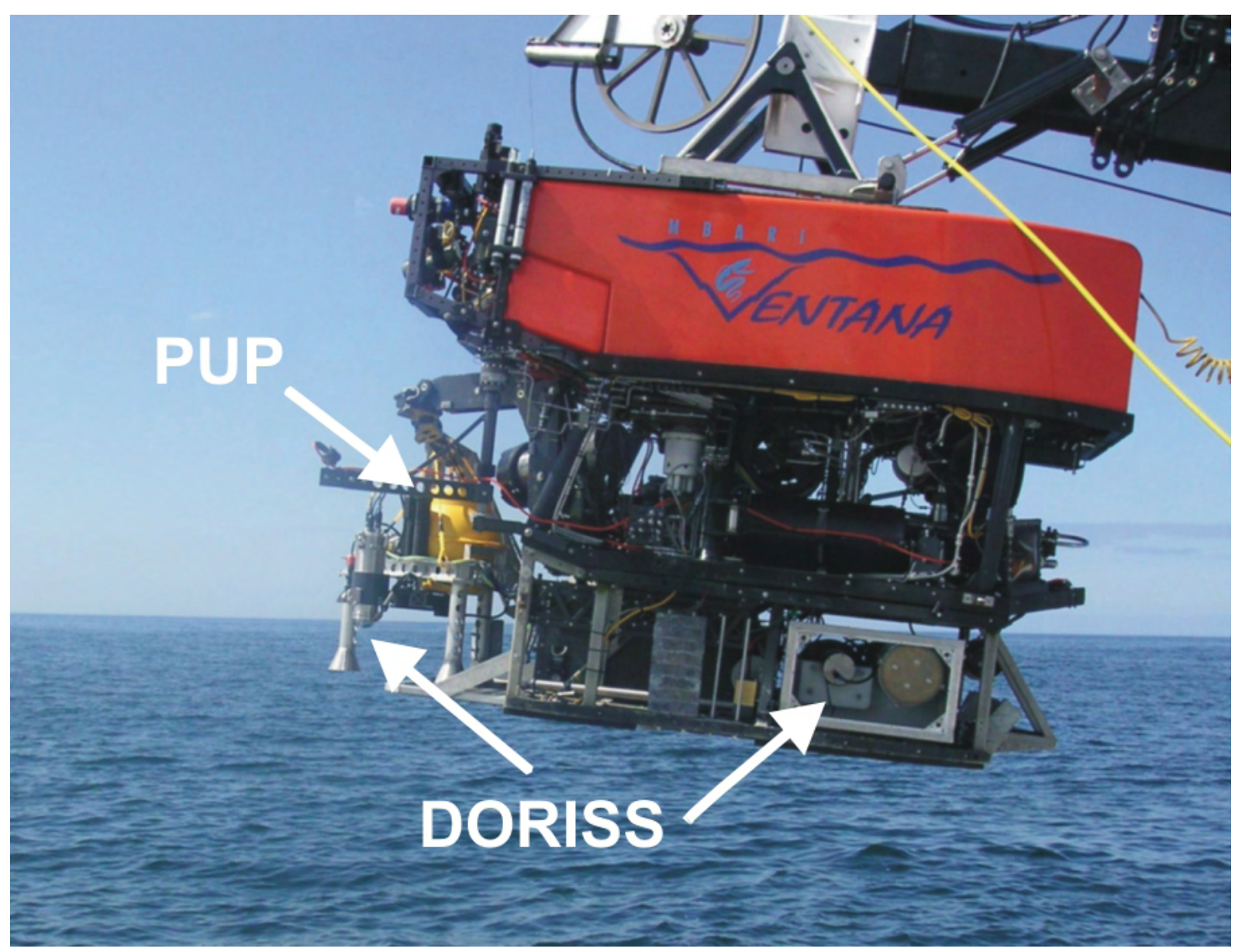


Figure 2

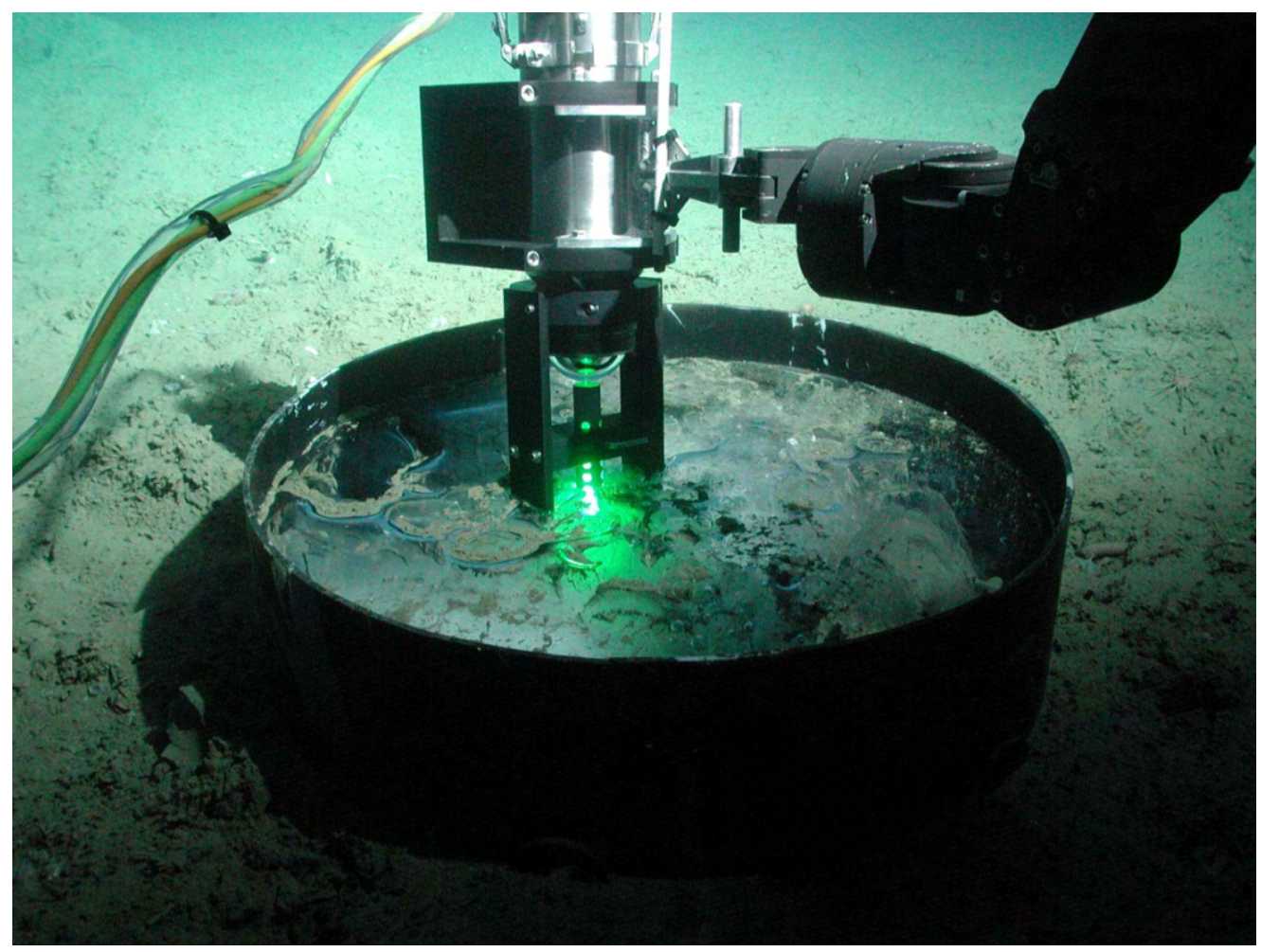


Figure 3
Click here to download Figure: Figure_3.eps

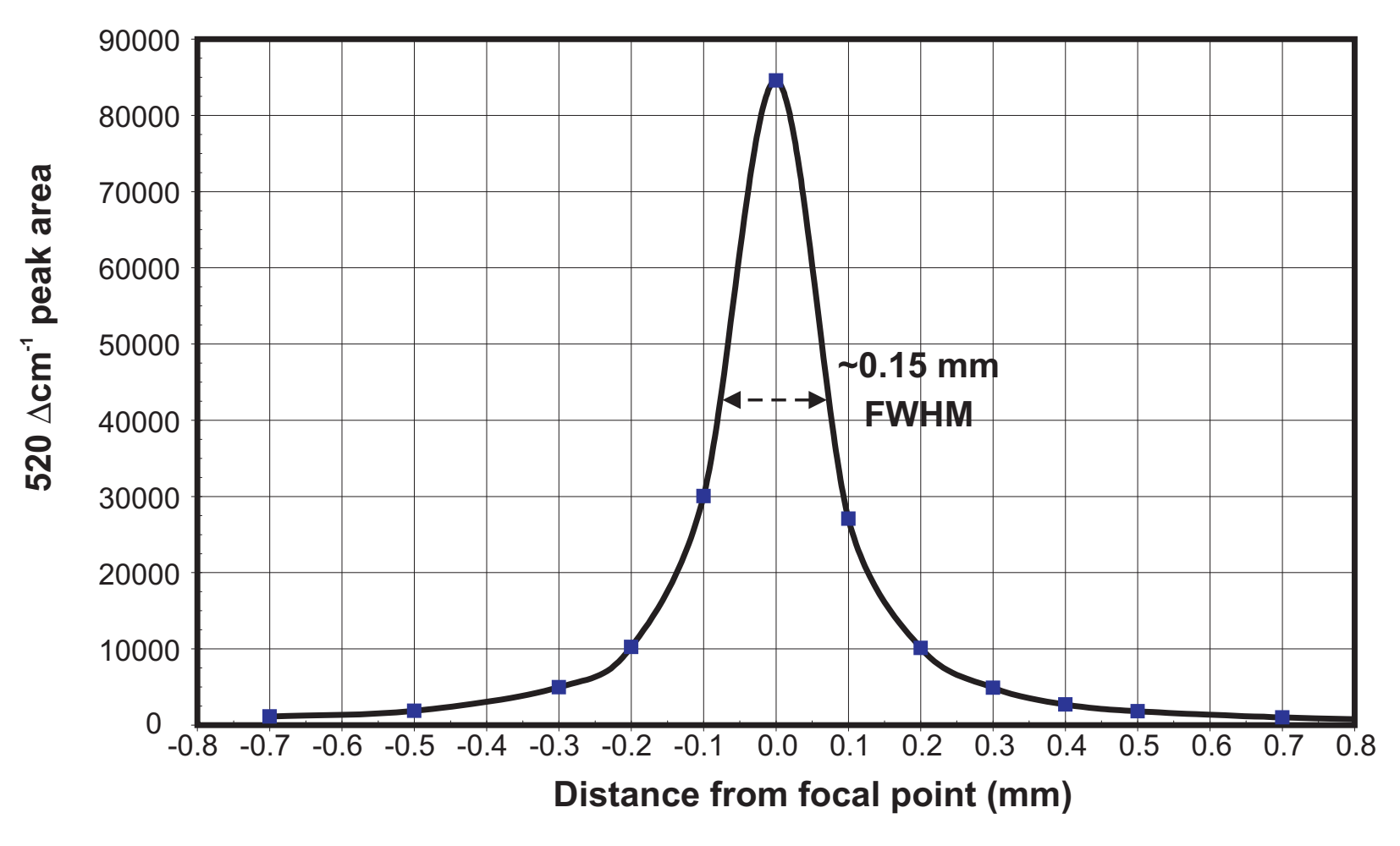

\section{Distance from focal point ( $\mathrm{mm})$}

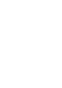


Figure 4
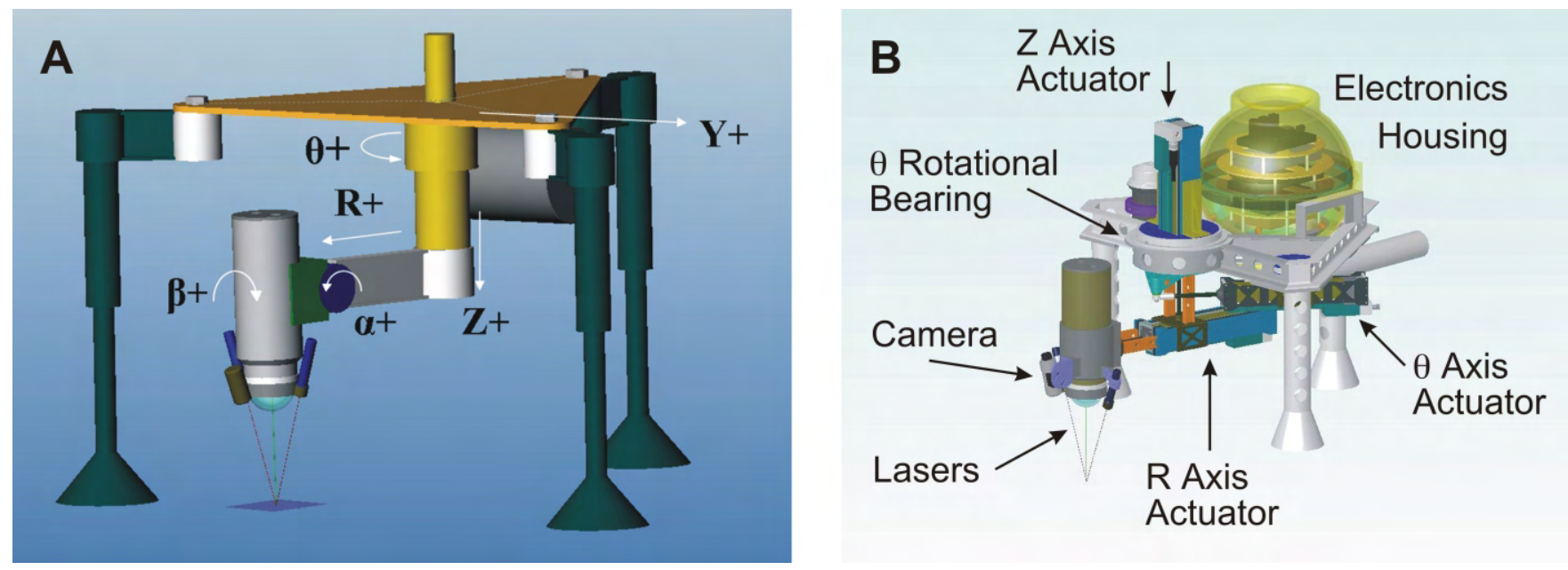
Figure 5

\section{System Block Diagram}

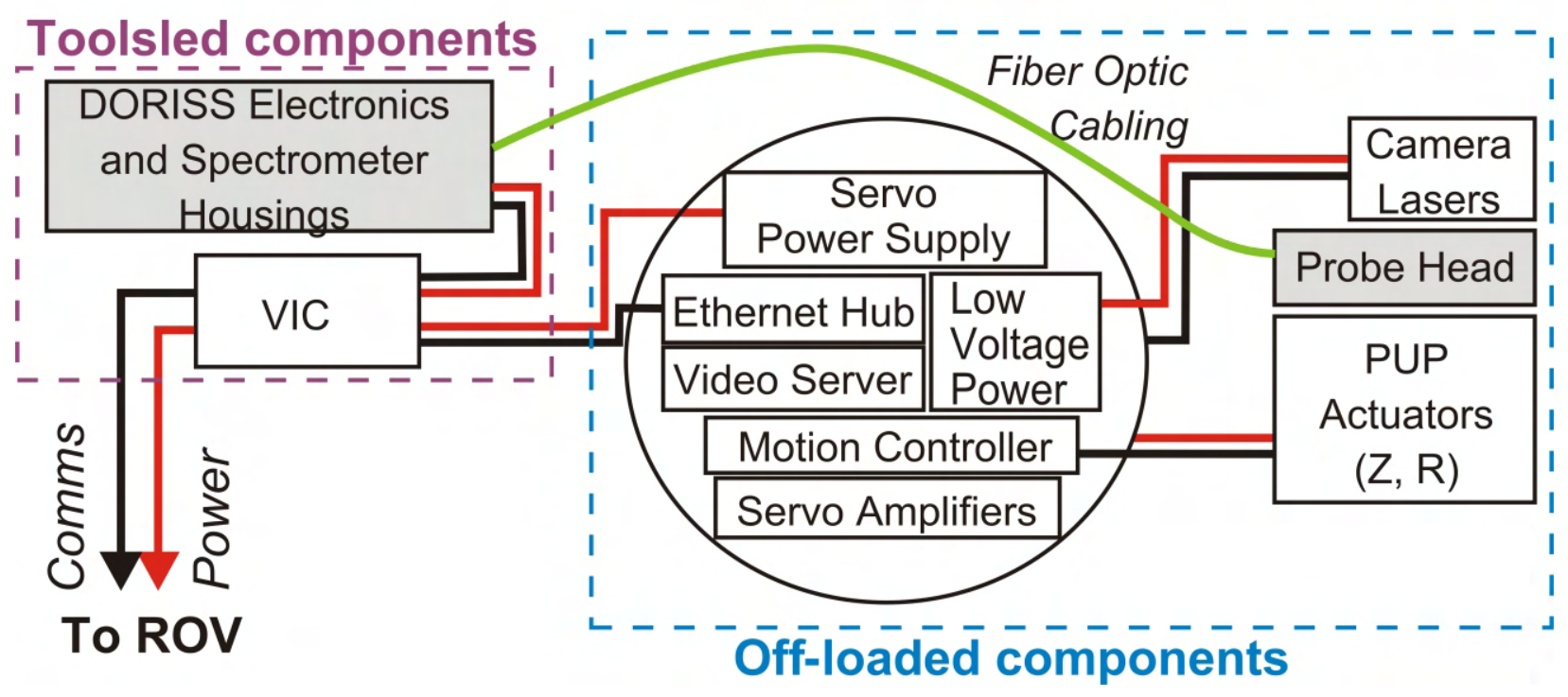


Figure 6
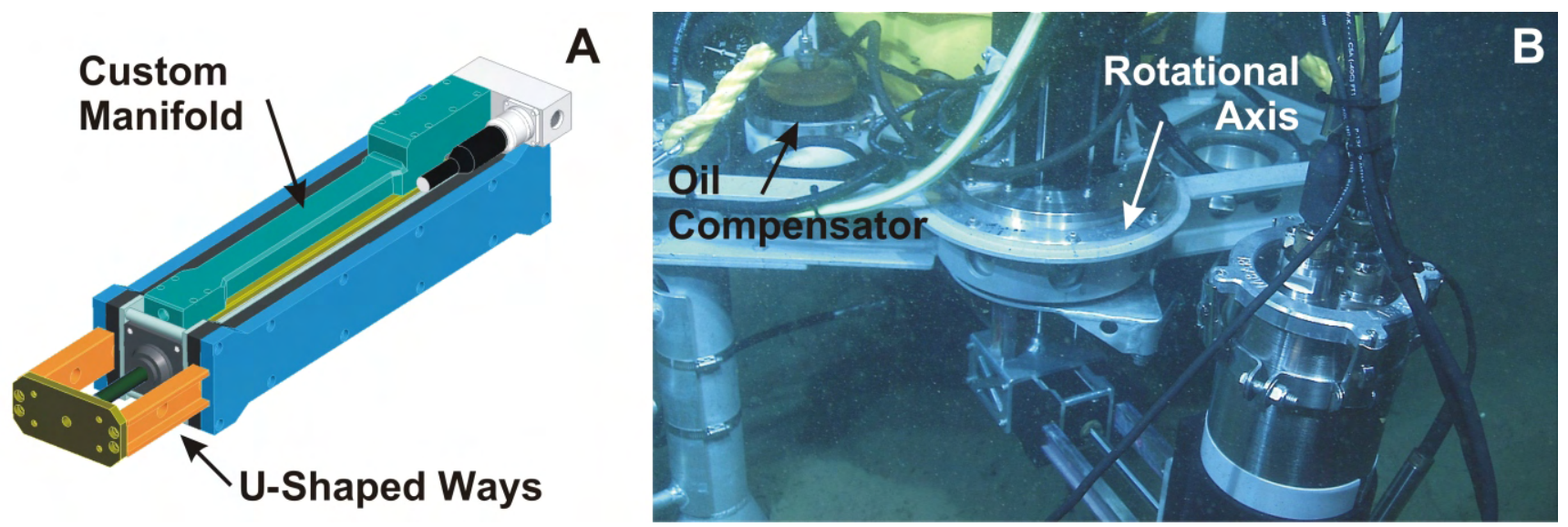
Figure 7

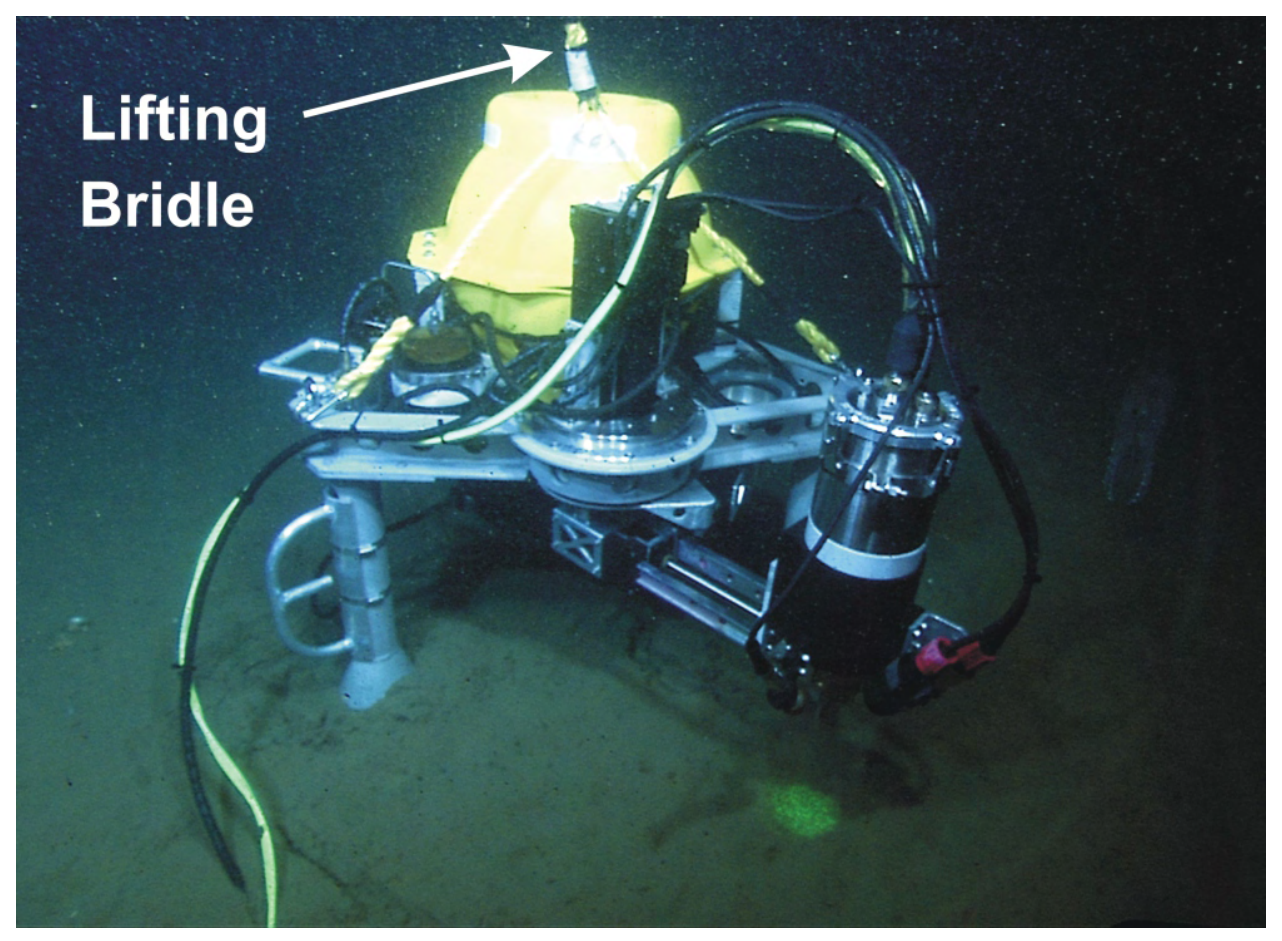


Figure 8

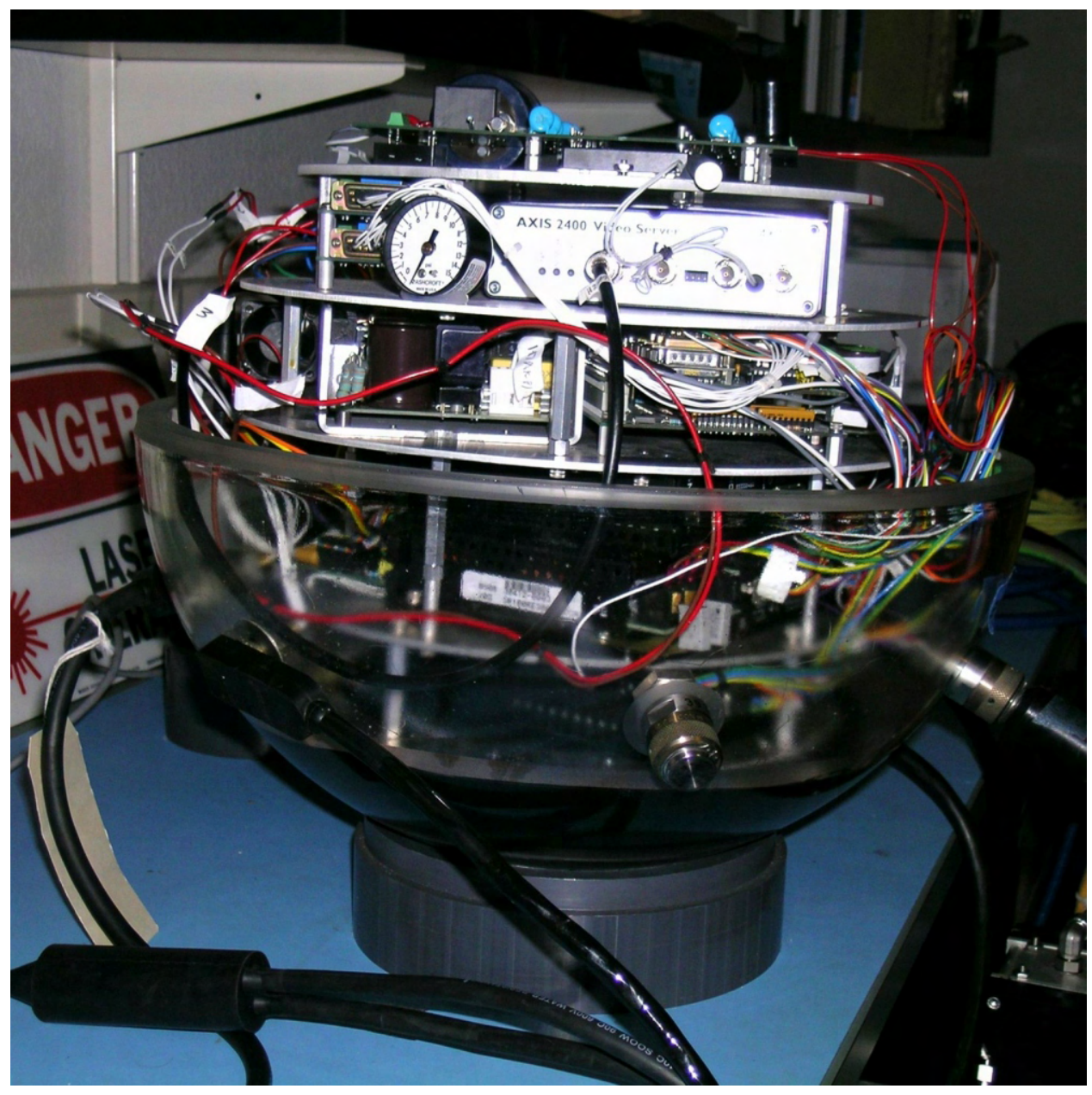


Figure 9

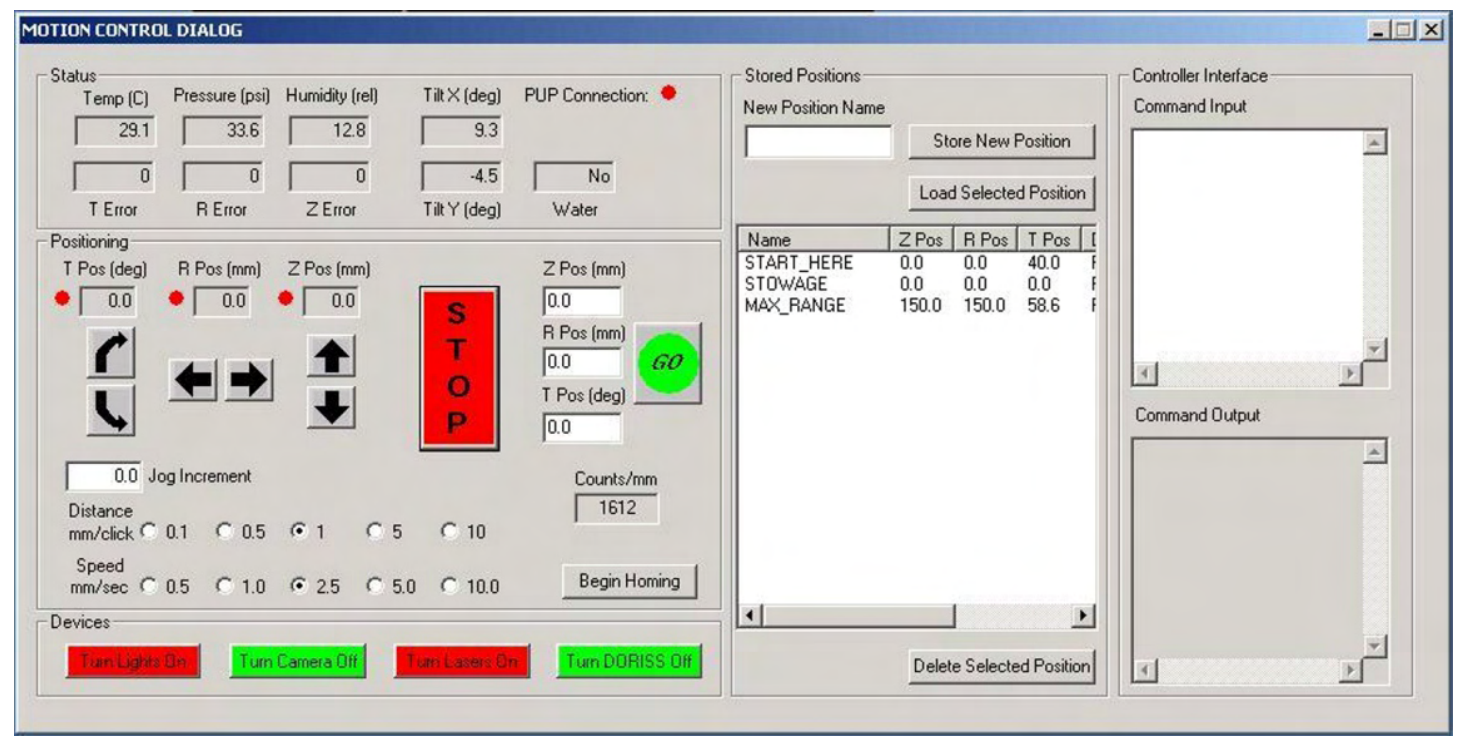




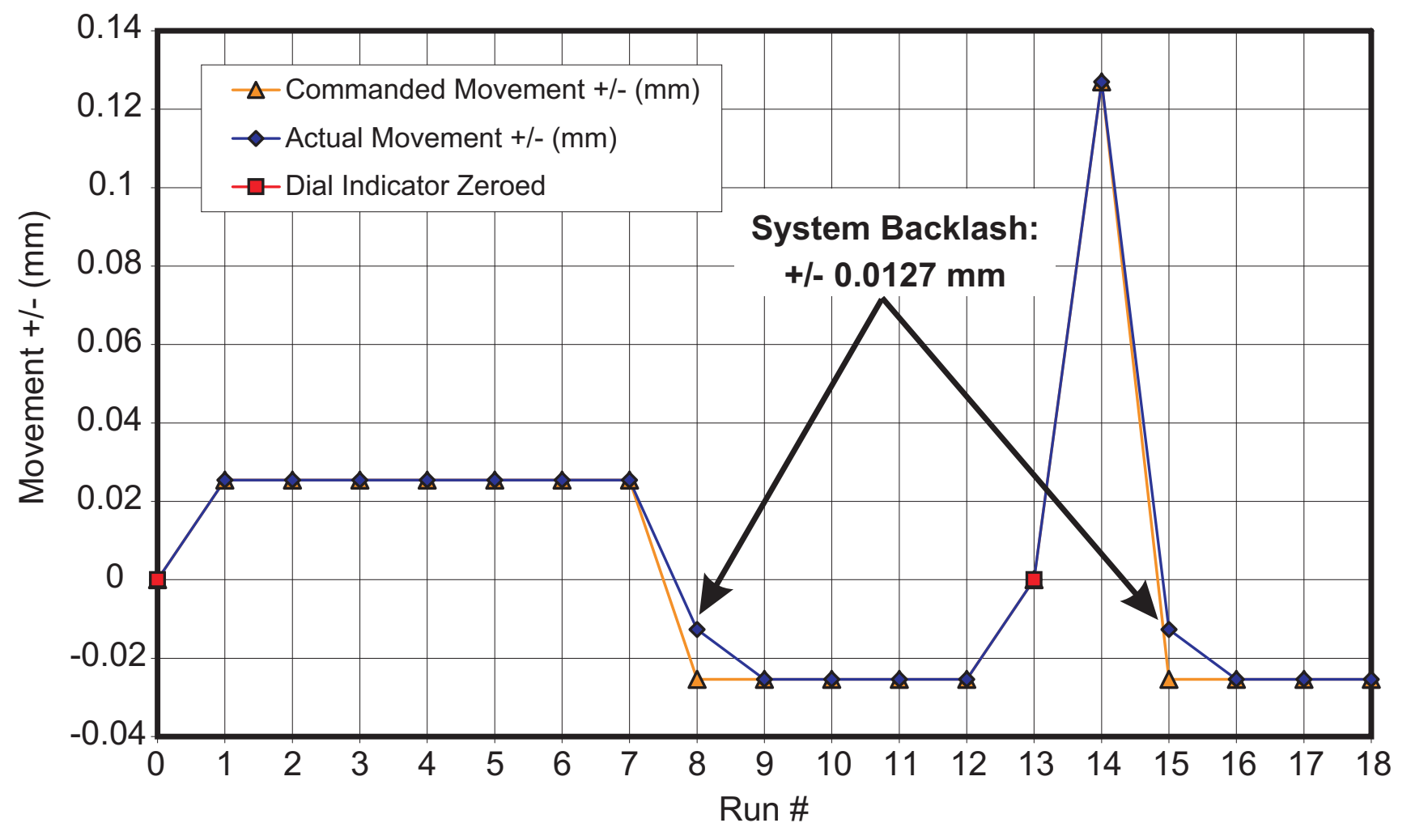


Figure 11
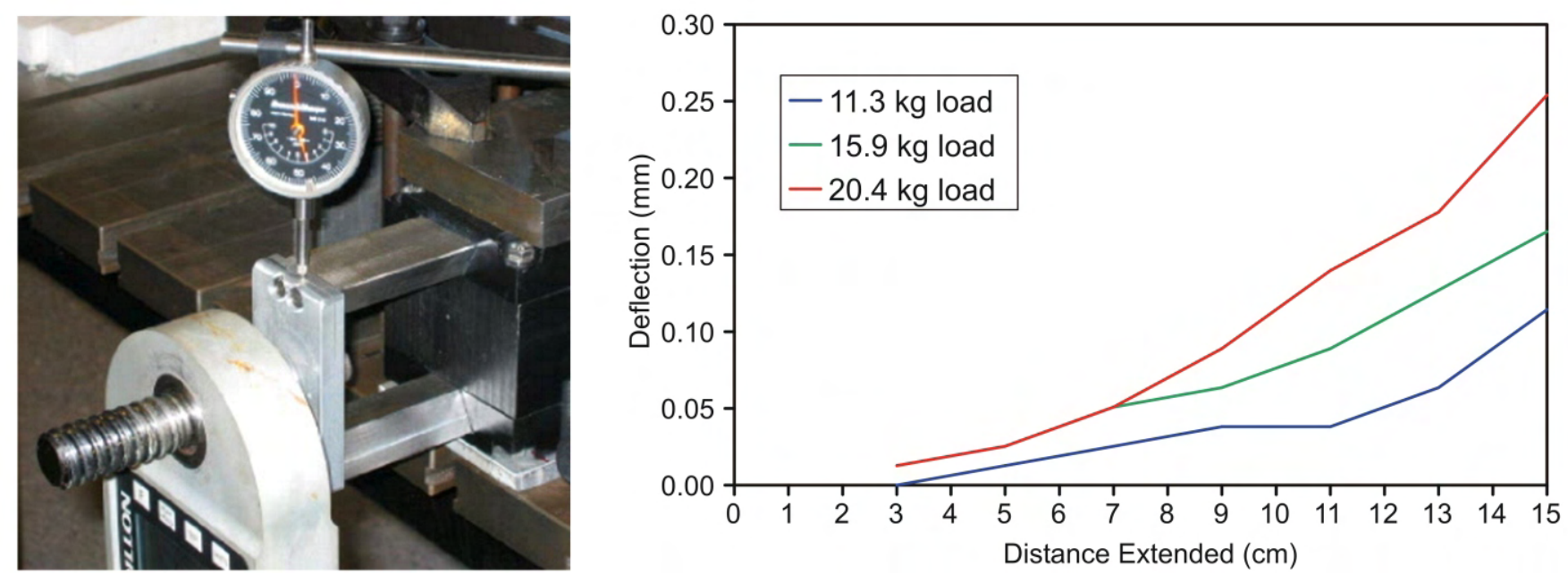


\section{Figure 12}

Click here to download Figure: Figure_12.eps
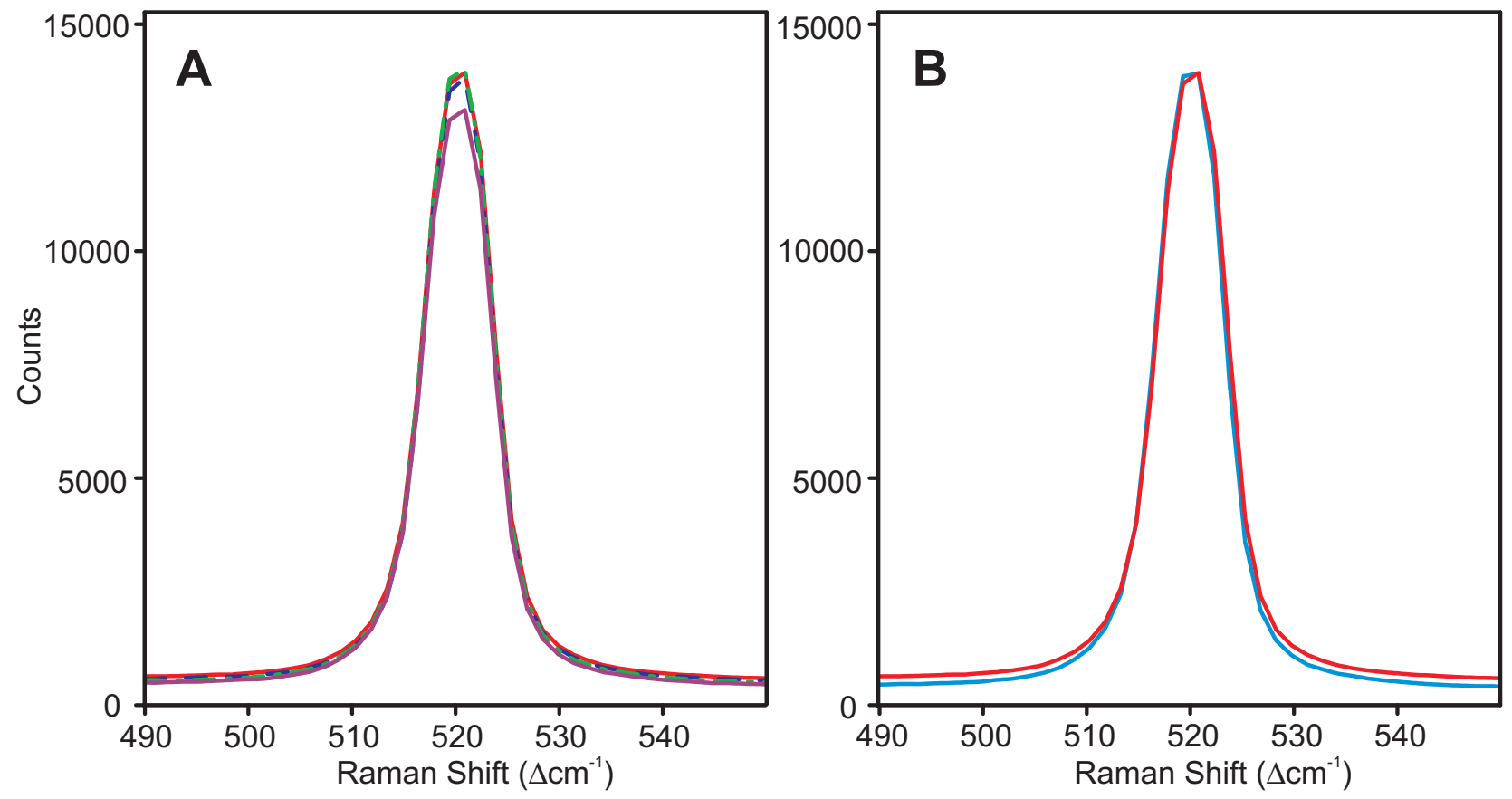

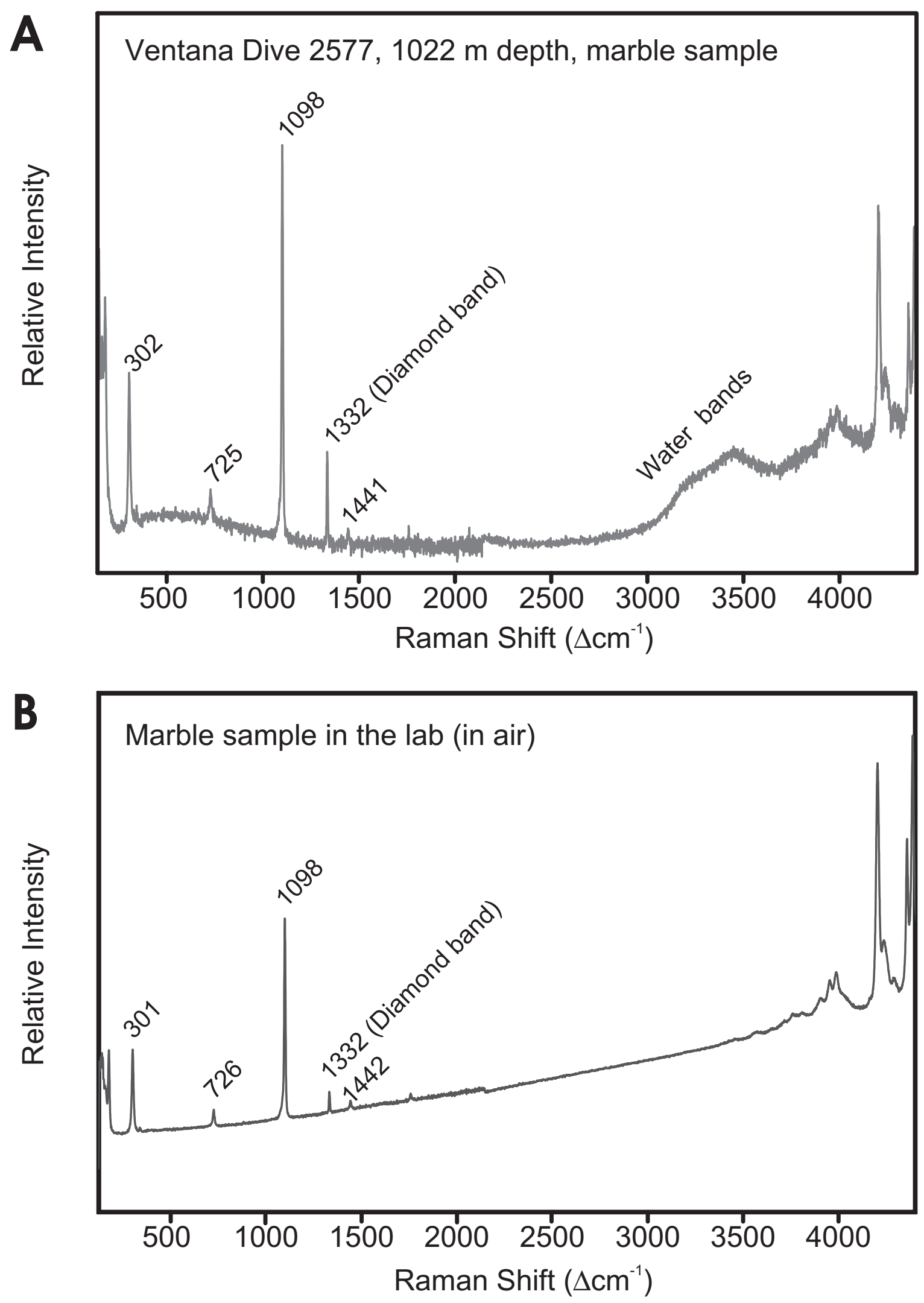
Click here to download high resolution image

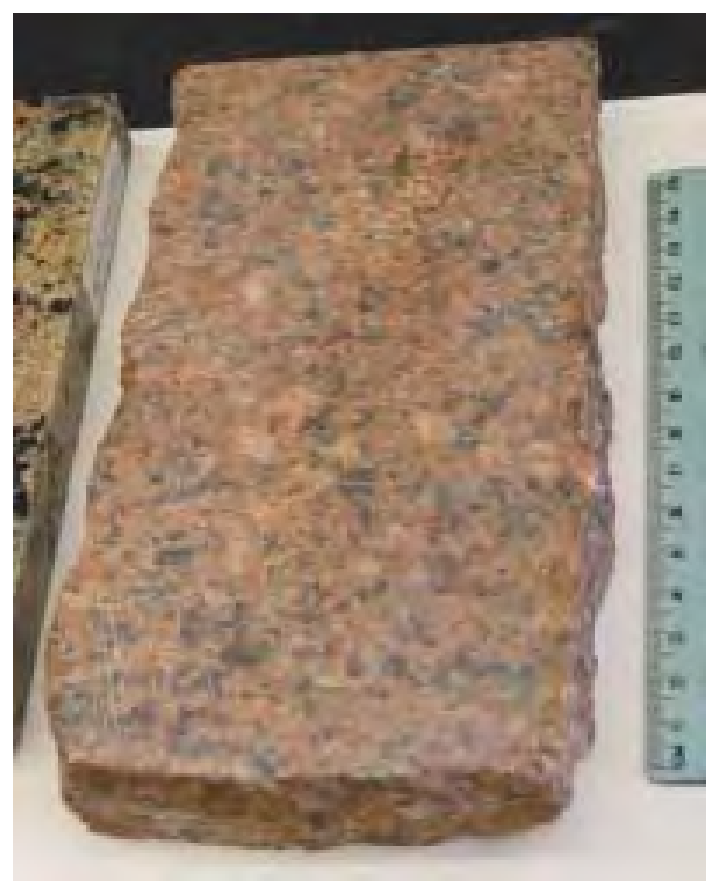




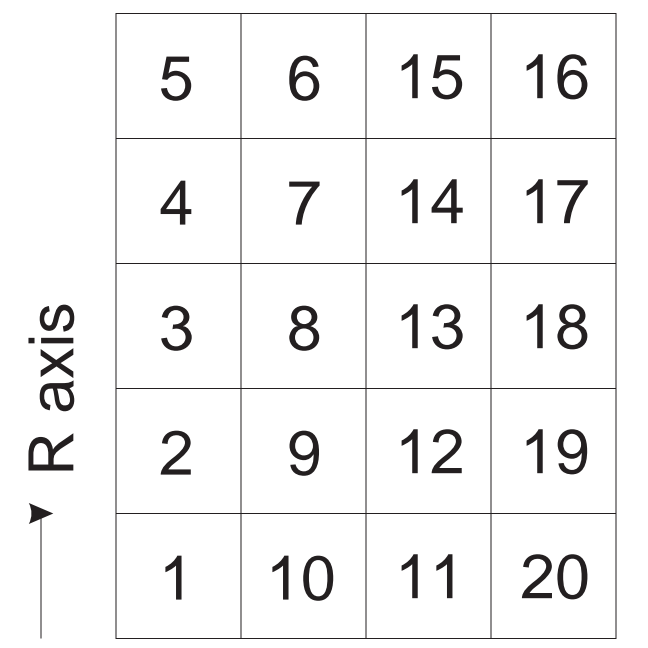

\begin{tabular}{|l|l|l|l|}
\hline Alb & Alb & Alb & Mic \\
\hline Alb & Alb & Alb & Mic \\
\hline Alb & Alb & Alb & Mic \\
\hline $\begin{array}{l}\text { Alb+ } \\
\text { Qtz }\end{array}$ & Alb & Alb & Mic \\
\hline Qtz & Alb & Alb & Mic \\
\hline
\end{tabular}

- Theta axis 
Ventana Dive 2578: Granite scan, $5 \mathrm{~mm}$ grid size

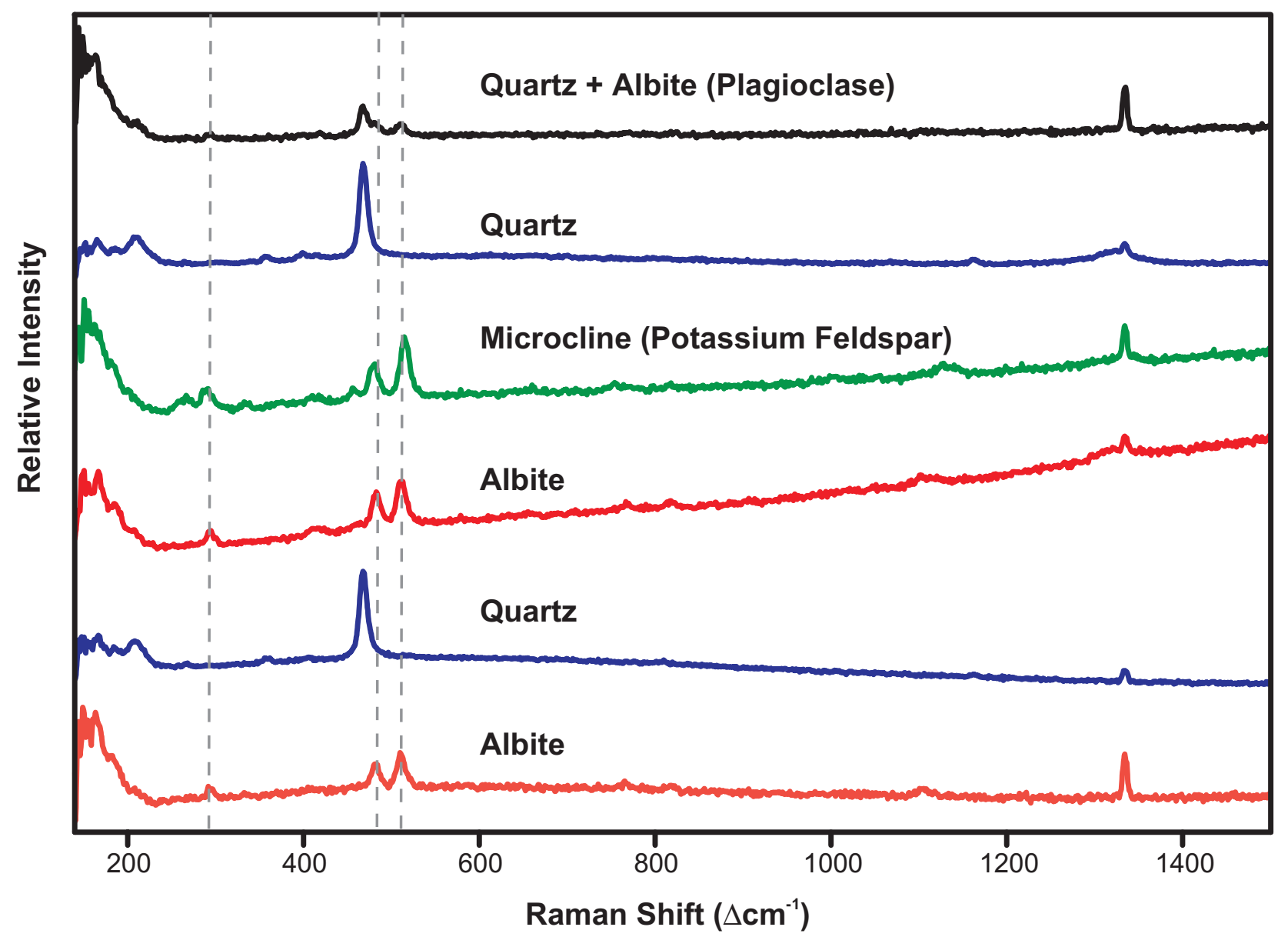




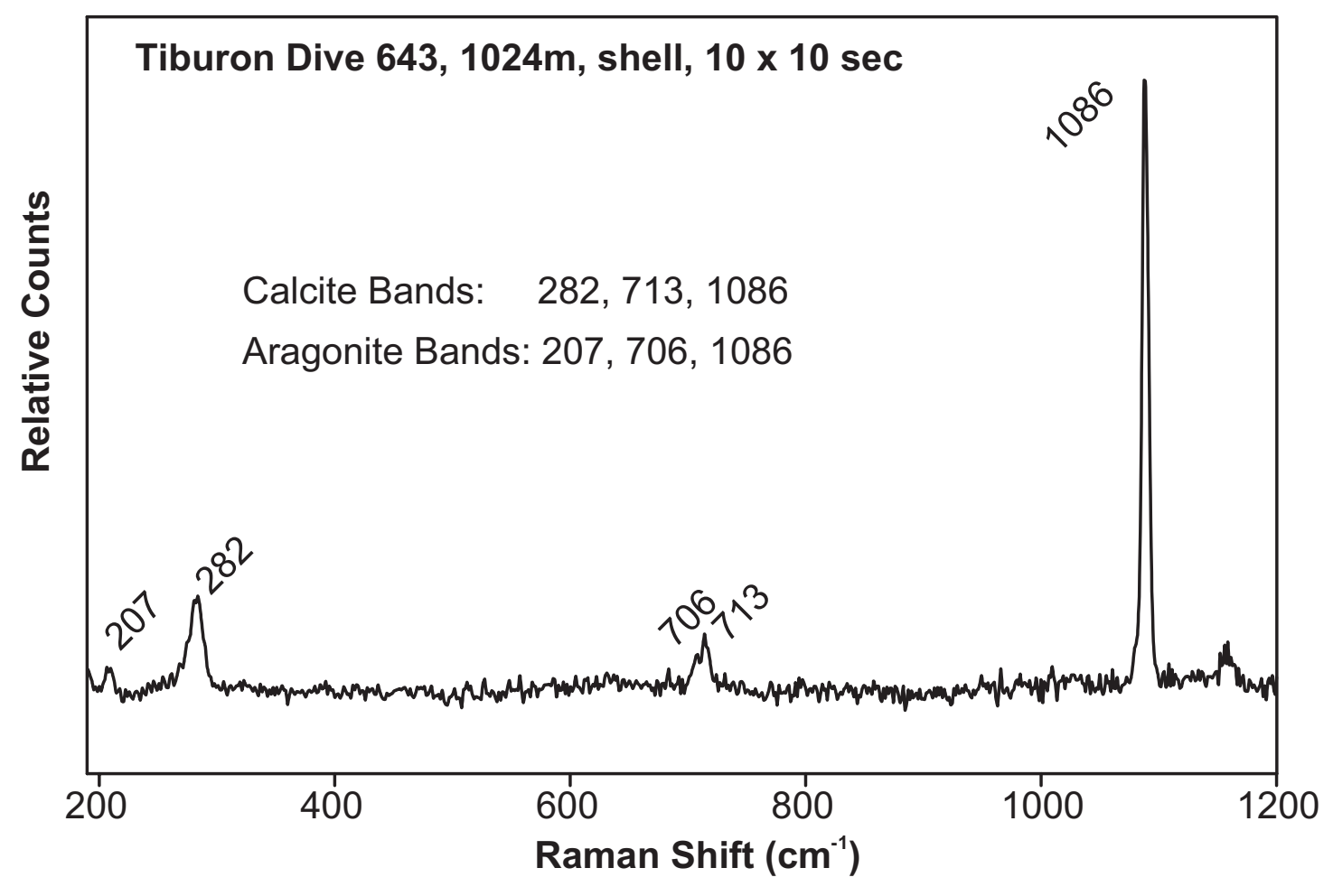


Ventana Dive 2578: Granite $0.1 \mathrm{~mm}$ profile

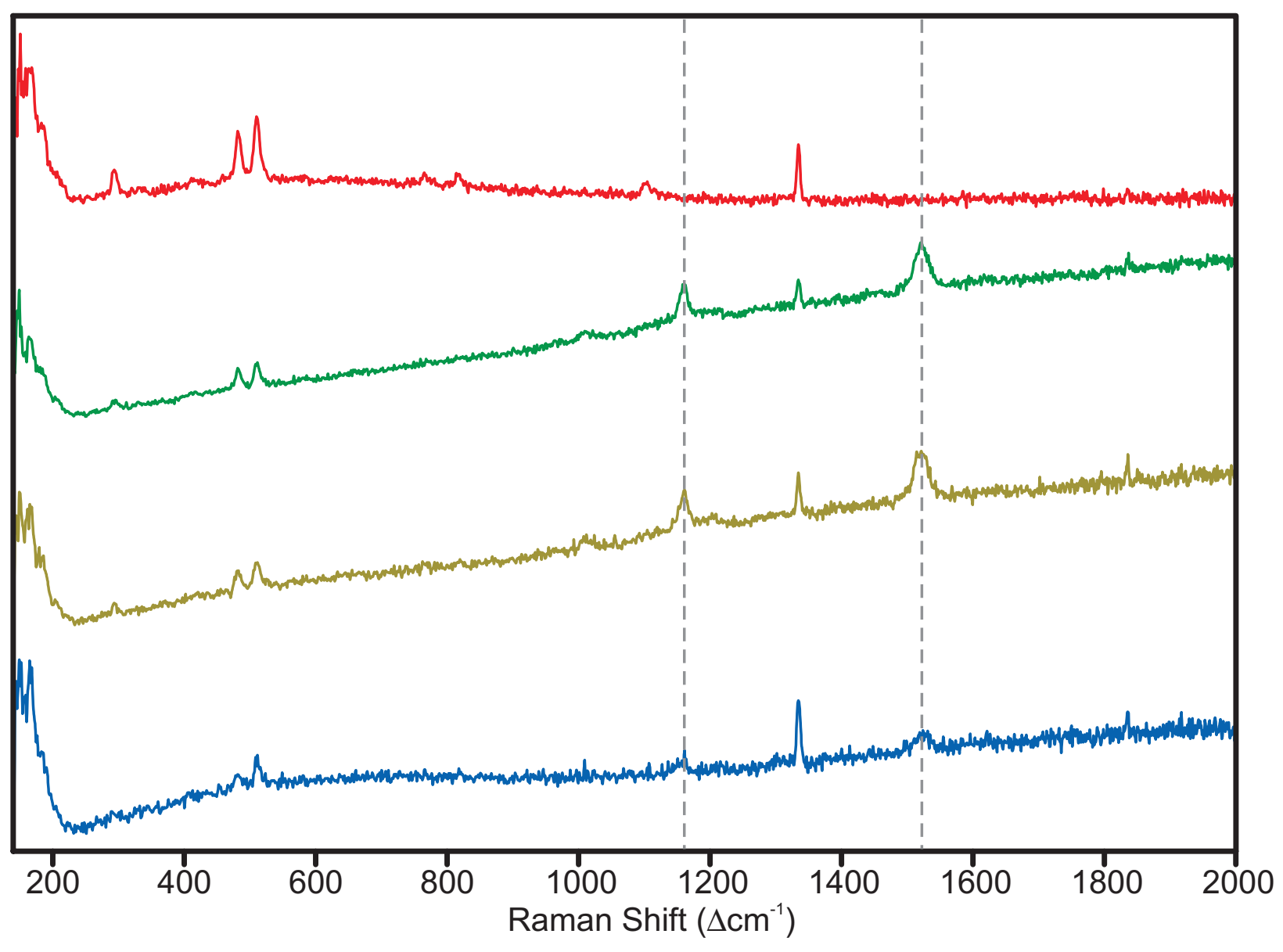

